The Geneva Papers on Risk and Insurance, 20 (No. 76, July 1995) 251-260

\title{
14th Geneva Lecture of the Geneva Association on Transnational Mergers and Transnational Experience in Insurance*
}

\author{
by J.L.M. Bartelds**
}

I shall present and discuss here my experience in transnational mergers and transnational activities in insurance: As Chairman of Fortis I have been deeply involved, together with my colleagues, in the development of an international financial services group called Fortis. Our insurance and banking companies operate in the Netherlands, Belgium, the United States, Spain, several other European countries and Australia. We tend to call ourselves a "cross-border and multi-cultural association", which seems to be a good explanation for why I am presenting some considerations about transnational mergers and insurance.

Before going into some details, it might be useful to specify further the subject and background of my presentation.

First of all, by saying something about insurance. This presentation is addressed to insurers and other people who are at least highly interested in insurance, my background and past experience being essentially related to insurance. However, Fortis is not just an insurer, but a financial services group. We are active in both insurance and banking. This explains why this analysis will also deal with bancassurance and the close relation between banking and insurance.

Secondly, I feel the necessity to comment on the word "transnational", which is mentioned twice in the title of my presentation. It does not mean the same thing in both places. Let's start with the end of the title: "transnational experience in insurance". I hate to disappoint the reader, but please note that I do not have any experience worth mentioning in this field. So don't expect me to say anything wise about transnational insurance in itself. Of course, Fortis controls insurance companies in a number of countries, just as AMEV did before 1990. Their core business, however, is mainly the local retail market, not transnational insurance-or banking.

* Lecture given in London, on March 7, 1995 at and with the collaboration of LIRMA (London Insurance and Reinsurance Market Association).

${ }^{* *}$ Chairman Executive Board, Fortis. 
The example of transnational insurance is of course Lloyds of London. The risks insured with Lloyds of London deal with events that might occur in virtually any country. And in broad outline, the nature of these risks is everywhere the same. The risks I am referring to are mainly big risks in the field of industry, transport and trade, and especially severe liability risks. The level of severity is something most of the Lloyds' Names have become fully aware of, more than anyone else in our industry.

Fortis companies however are mainly active in the personal lines. And as the reader probably knows, these lines differ per country. "All business is local business", is a statement that applies to most of the Fortis companies around the world.

One could argue that in Europe this has changed, due to the European Union. However, some legal limitations still exist. Besides, there are major differences in national prosperity and in social security arrangements. And don't forget the differences in methods of distribution. Although I mention it last, I think that this difference is the most important one, because the success of a financial services company depends heavily on its distribution channels. To develop interesting and well-priced products is only one thing; without an efficient distribution network you will not be successful.

Fortis therefore still considers a regionally oriented strategy to be the best, as it enables the company to take into account all financial, cultural and other specific characteristics of the country. A major condition however, is the achievement of sufficient volume. In every market and in every region, a company needs to have sufficient volumes, or, in other words, a healthy relationship between costs and revenues. This is by the way an attitude which seems to have changed through the years: in the seventies, many insurers focused on regional spread only and not so much on volume too. In that time, you could generate profit with rather small operations. Since then however, margins have been shrinking and many insurers - and Fortis is among them - experienced the disadvantages of such relatively small businesses. As you know, such smaller businesses also require management attention, and often out of all proportion to their size. And their limited size does not mean that they cannot cause considerable losses.

My comments on transnational insurance and Fortis' focus on regions and local business would not be complete without saying something about the so called "Third Directives". Since the middle of 1994 these directives allow for cross-border sales, thus offering opportunities for transnational financial services activities within Europe. As a result of this, our Luxemburg bank and insurance companies have sold savings and investments products to a considerable number of non-Luxemburg based clients.

During 1994, this has proved to be a growth market, as far as Fortis is concerned especially in Belgium. For 1995 we do not expect this development to change. On the contrary I would say: we expect that not only our Belgian operations, but also our companies in, for example, France and the Netherlands, will start to exploit the opportunities offered by the Luxemburg market.

Nevertheless, Fortis companies are and will continue to be active mainly in their own home markets. They are so-called domestic companies, combined in a group of many of such enterprises. Therefore, we tend to call Fortis not only a cross-border and multi-cultural association, but also a multidomestic group. We act locally, but also think globally. We strive 
for "exchange of expertise" and "exploitation of synergies" at a group level. But at the same time we respect all the characteristics of countries and customers that determine our market environments.

Those were the comments I wanted to make concerning "transnational experiences in insurance". Before going to talk about transnational mergers, I now would like to discuss some key issues about bancassurance as well.

As I already noted, Fortis is active in banking as well as in insurance, or - it would be better to say - in financial services. I mention this explicitly, because I am convinced that in the near future, the differences between banking and insurance products will fade away further. The only really relevant distinction will be the channel through which the financial services products are distributed. This does not mean that every channel can distribute exactly the same products. Complicated pension products for example, seem best suited for distribution through brokers, whereas bank branches are a very good distribution channel for, for example, a simple savings insurance policy. Especially in the Netherlands, Belgium and Spain, Fortis follows a multi-channel distribution strategy. In these countries we strive to offer our customers a full range of financial services, distributed through tied and independent agents as well as bank branches. By the way, this full financial services approach, or bancassurance if you prefer, is mainly applicable to the retail market, to individual customers and small and mediumsized companies.

It is in these customer segments, that it pays off to offer a full range of financial services, to strive for integrated sales, taking into account the available budget and financial planning of the customer. It is in this field, that the real synergies between a bank and an insurance company exist. There is no synergy between a wholesale bank and a retail insurer.

Before I present to the reader more about our transnational group Fortis, let's take a look at transnational mergers in general. As we all know, large companies usually stem from concentrations, like joint ventures, acquisitions and mergers. Most of such companies clearly retain the character of only one country. There are however also some companies which are truly transnational. Such companies - or groups - normally have two parent companies of two different nationalities. From a purely legal point of view, one might say that real mergers on equal terms between companies from different countries do not occur, because these transnational companies have two parent companies. Normally, these parents strive to keep their own identity and to remain part of their domestic society. This is by the way very understandable. A concern which belongs nowhere would be without a home. It would have lost its roots. Forming part of a community with ties to a country is certainly important and of great value.

However, I am not a person who considers things primarily from a purely formal and legal point of view. I prefer to take a factual and more commercial standpoint. And if the reader does so too, we will see that there are indeed some companies, which are truly international, multinational and transnational. They do not only operate across national borders. They are also run by a cross-border management.

In the Netherlands and the UK, we have several transnational groups. We have Royal Dutch/Shell-Group and Unilever, which have both been in existence for quite some decades already, and we have Reed-Elsevier, which was created about two years ago. Another very famous transnational company is Asea Brown Boveri, a Swedish/Swiss concern. And there is of course Fortis, which was created in 1990. 
Other examples in Europe of such really transnational companies, are difficult to find however. In my view, this is astonishing, because when one takes into account Europe's position in the world, when one compares Europe with the US and Japan, it is clear that the development of the European Union is essential, and that we also need to create truly European companies. If one wishes to compete on a world-wide scale, volume and financial strength are essential, no longer just in one national market, but on a European scale too. Taking this into account you would expect more transnational mergers within Europe, certainly if companies have relatively small home markets. Such transnational mergers in Europe will result in companies with a better geographical spread, in a combination of human resources and expertise, and in a combination of financial resources, which can be used thereafter for further expansion in new growth areas, like Eastern Europe and South East Asia. Of course, such transnational mergers do not offer advantages only. There are also a lot of complicating factors, such as the lack of a really European legal structure for companies, and the considerable differences in, for example, shareholder structures, price/ earnings ratios, tax treatment of dividend payments, accounting rules, protective measures and of course cultures. However, despite these complicating factors, it is possible to achieve transnational mergers. Fortis is an example of that.

Let me now summarize the most important characteristics of my group:

- Fortis is an international financial services group, with its roots in Belgium and the Netherlands. In 1990, insurer AMEV and savings bank VSB decided to merge their operations, thus realizing the first merger between a bank and an insurer in the Netherlands.

In the same year, AMEV, VSB and AG Group combined their operating activities into one group and thus created Fortis. Fortis is the first and so far the only transnational combination on an equal basis in the European financial services industry. It has two parent companies, Fortis AMEV and Fortis AG, which own $50 \%$ of Fortis each.

- Our joining of forces offered advantages for AMEV as well as for AG.

These advantages lie in the field of size and strength, spread of income and financial efficiency.

In 1989, AG had a total income of \pm ECU 1.7 billion (or \pm GBP 1.2 ); $87 \%$ of its total income was realized in Belgium. In the same year, AMEV's total income amounted to \pm ECU 4.6 billion (or GBP 3.4 billion). $44 \%$ of AMEV's total income was realized in the Netherlands, and $38 \%$ in the United States. As of 1990, both companies own $50 \%$ of Fortis, which now has a total income of more than ECU 16 billion, and which has a much better spread, geographically speaking, and by line of business.

Also in 1989, both AMEV and AG were rather big fishes in rather small ponds. Nowadays, we are both much bigger fishes in considerably bigger ponds.

Again in 1989 , both companies were following a growth strategy. We were both convinced of the necessity of sufficient volume, not only in single markets but also on a European and world-wide scale.

However, to achieve sufficient volume internationally speaking, separately, would require each of us to make huge investments. Instead of doing that, we opted for transnational cooperation and created Fortis. For each of us it would have been impossible to build a volume and spread as Fortis has today. 
Another major advantage of merging our operations into Fortis was the "financial efficiency". As we all know, an acquisition is rather expensive for the acquirer. Shareholders of the acquired company have to be paid considerable funds, which they normally reinvest in another company, usually a competitor of the acquired company. By merging our operations into Fortis, we avoided this. Besides, we did not have to pay any goodwill. We could simply add up our capitals. This gave us the financial strength which we used for our growth strategy. By merging our operations into Fortis we optimally exploited the funds present in both companies.

- Another advantage was the limited overlap. We did not have to implement a large integration program; this was only necessary at the top level. This enabled us to start immediately our expansion program after the finalization of our merger.

- The creation of Fortis was a win-win situation for both AG and AMEV. But do not think we did not have to face the disadvantages and complicating factors which I mentioned before.

Fortis' two parent companies had and still have their own identity. They differ considerably from each other. Fortis AG has shares with voting rights and close shareholders who appoint members of the Board of Directors. Fortis AMEV has depositary receipts, without voting rights. Both have in the end a protective effect, but there is a huge difference between these situations. In Belgium, executives and non-executives together form the Board of Directors whereas in the Netherlands, only non-executives are members of the Supervisory Board. These are only some examples of the many differences between the two parent companies of Fortis. It goes without saying that these differences did not simplify our discussions in 1989 and 1990.

However, we overcame these and other complicating factors and succeeded in our wish to join forces, by combining our operations, while preserving the two parent companies.

- As a result Fortis is not a legal entity. From a legal point of view, Fortis is not a merger. But from a factual and economic point of view, Fortis is clearly one concern, owned by two parent companies, managed by a multicultural and cross-border management.

We have unity of management, unity of strategy, and unity of resources. Our name, Fortis, underlines these unities as well as the strength of our group.

- Fortis' unity of management is shown in the existence of one Management Board, one Executive Board and one Supervisory Board. Our management structure includes four Chief Executive Officers, responsible for the United States, the Netherlands, Belgium and our other international activities. This regionally oriented management structure combines a strong corporate governance with sufficient regional authority.

And this enables our operations to respect the individual characteristics of a country and its people.

- Nowadays, Fortis is active in Western Europe, the United States and Australia. Fortis companies are, among others, AMEV Nederland and VSB Groep in the Netherlands, AG 1824, ASLK-CGER-Bank and ASLK-CGER-Insurance in Belgium and Fortis, Inc. and its operating companies in the USA.

In the Benelux countries, we follow a multi-channel full financial services strategy. In Spain we follow a similar strategy, in co-operation with Spain's largest savings bank "La Caixa". In the United States we strive for leading positions in specialized insurance and investment products. 
Fortis is following a growth strategy. We aim to be a leading financial services group. Since the creation of Fortis in 1990, we have invested more than ECU 1 billion in new acquisitions, which was possible because of the financial efficiency of our merger.

In 1994, Fortis has realized a net profit of ECU 549 million. The balance sheet amounts over ECU 100 billion. In 1994, Fortis realized a total income of ECU 15 billion. We have more than 32,000 employees. In the latest Fortune ranking of large diversified financial companies, we are ranked 10 when total assets are taken as criterion.

- In the years to come we want to expand our activities further. Autonomously as well as through external growth. At the same time, internal growth and the exploitation of synergy opportunities will play an essential part.

- A final fact I cannot refrain from mentioning, is the name change of Fortis' parent companies. Fortis' two parent companies have their own identity and certainly differ from each other. However, they share their interest in the good and healthy development of Fortis. In order to stress their identification with Fortis, both parent companies changed their corporate names in June 1994. They both added the Fortis name to their original name. In 1990, we could not imagine that this decision could already be taken so soon. A corporate name is a very important element of a corporate identity. And despite the differences between the two parents and their wish to preserve their own identity, both parents changed their corporate names!

However, these are only some facts and figures about Fortis. They do not reveal much about our transnationality. What they do show however, is that Fortis is a real success: looking at the results we have achieved and the strategic steps we have taken since 1990, I think Fortis has indeed proved to be a successful transnational group of financial services companies. I can imagine the reader would like to know our key success factors. What are the major reasons for the successful development of Fortis? I intend to answer this question during the next part of this presentation. But don't expect any magical formulas, because there aren't any. I cannot provide any trick: what I can do however, is to underline the importance of some basic principles, which proved to be effective in our case.

First of all, it is important to stress that every acquisition, merger or alliance causes a cultural shock. This is true for transnational cooperations. But it is also true for cooperations which do not cross any national borders. Each company has its own way of working, its own style and atmosphere, its own way of doing business with each other. When the fields of activity of two companies differ, there are even more differences to cope with. A retail bank like VSB is quite different from an insurer like AMEV. And an industrial insurer like Interlloyd is nothing like a personal line insurer.

Of course, one has to deal with these differences too when one decides to go for transnational cooperation. And in that case the differences are even bigger. Belgium and the Netherlands are both small countries and they lie very close to each other. They are sometimes called "the low countries", just as people speak in one breath about the Baltic states. This suggests that Belgium and The Netherlands as well as their inhabitants are very much alike, which is absolutely not the case. The Belgian culture is very different from the Dutch culture, and that is not only a question of languages, although even minor differences in language can sometimes be the reason for misunderstanding or confusion. The Netherlands and Belgium are really two different countries, just like for example France and the UK. 
This does not mean that one should worry about the effectiveness of Fortis. Within our group, there is a very good and positive cooperation between Belgian, Dutch, US, Spanish, and other executives. Fortis' multicultural composition offers challenges as well as opportunities. It is an enrichment and an inspiration. But one must be aware of the differences. One has to take them into account, in order to avoid misunderstandings, which can arise rather easily. Things which are completely normal in one country, can be unusual or different in another country. Decision-making processes are not the same in every country. And the way people express their agreement or disagreement can vary substantially.

What counts however, is the firm desire to cooperate. You absolutely need harmony and unanimity.

To get them, at least two things are essential.

First of all, one needs to agree upon what one wishes to achieve. A clear common vision and objectives are essential.

This was why AG's and AMEV's initial discussions focused mainly on a common business plan. We did not start talking about the underlying values of our companies, but about our business, our present and future strategy, the advantages of a possible cooperation. During these discussions we discovered that we shared the same vision on future developments in the financial services industry. And we concluded that joining our forces together in a single group would create a win-win situation for all parties involved.

We took our time for these discussions. Our pre-merger phase lasted about two years, as we wished to be absolutely sure that we really shared the same vision and objectives.

The second thing which is essential for a successful transnational cooperation is positive "human chemistry". Because at the beginning and at the end, it all comes down to people. This may sound easy. But it is not, or at least not always. Because this requirement means that the people involved need to have mutual respect and empathy. Besides, they should have the modesty and willingness to share power. No-one should have any intention to dominate. These requirements should first be met at the top level.

There is no doubt that the very good personal relationship and cooperation between Fortis' other Chairman, Maurice Lippens, and myself, has been and still is essential for Fortis.

I personally believe that the creation of Fortis had the advantage that the two Chairmen did not have only a few years left before their retirement. Maurice Lippens and I, as founding fathers of Fortis, had and still have a sufficient number of years to work on the further development of Fortis and to diffuse the Fortis feeling among the management and employees of our group. Because the willingness to cooperate and not to dominate, the readiness to share power, and the necessary mutual respect and empathy have to be present in all layers of our organisation. Everybody has to adopt the real group spirit. That's what we have worked for', that's what has happened within Fortis since 1990, and that's also what should continue during the years to come.

Just to give some examples about this mutual respect and modesty:

Within Fortis, we respect each other's company cultures. The way we celebrate anniversaries and jubilees varies from one company to another, and so do for example local reporting rules and employees' participation systems. This does not mean that we have a clear national division in our Executive Board. On the contrary. Some time ago, I was asked for the 
numbers of Belgian and of Dutch Executive Board members. Well, I had to think quite deeply before being able to give the correct numbers. This at least shows how little we are focused on the nationality of our Executive Board members.

As far as practical details are concerned, we do take into account the Belgian/Dutch roots of Fortis. Board meetings take place alternately in Utrecht and Brussels; the Chairman-ship of meetings alternates as well. The staff departments are centralized in Utrecht and Brussels, but we strive for an adequate exchange and communication between the head offices by creating bi- or even multinational, cross-border staff departments. By the way, our staff employees will in the future probably be employed by one European Economic Interest Grouping, as this will enable us to harmonize labour conditions and give the employees the sense of having really one employer, instead of the present situation, in which our staff executives are employees of several operating companies in Belgium and the Netherlands. During meetings, each board member speaks the language he prefers. The only exception to this is the Executive Board. As our CEO in the USA is a member of the Executive Board as well, these meetings take place in English.

There is only one point where Utrecht has entirely adopted a Belgian custom. Also in Utrecht, we introduced the so-called Belgian lunch. As the reader most probably knows, the informality of a lunch creates the opportunity to converse "off the record" and to improve further personal contacts. We found out that this is much easier during a Belgian lunch than during a Dutch lunch with only some sandwiches and milk.

But, whether it is the lunch or the language, cultural differences will continue to exist.

Is that a disadvantage within a transnational organisation like Fortis? We of Fortis think it is not. On the contrary, we consider it positive. Cultural differences are inspiring and exciting. They offer you the chance of learning anew every day. They offer challenges. On the other hand we admit that transnational mergers are not always successful.

Look at for example Hoogovens and Estel or at the initiative of the Dutch AMRO Bank and the Belgian Générale de Banque. These initiatives did not succeed. Which makes us, by the way, even more proud of the successful development of Fortis.

\section{Let us summarize the major points:}

Transnational groups like Fortis have the strength and power of a multinational organisation. We have more than 32,000 well trained, experienced and highly motivated employees and a balance sheet total of more than ECU 100 billion.

On the other hand, Fortis has the local expertise of each domestic company, which ties in to the local networks and the national culture. We are confident that this combination will be difficult to beat.

When Fortis was created, AG and AMEV were convinced of the necessity of sufficient volume. The creation of Fortis was a result of this conviction. Besides, it offered us the opportunity to combine our expertise and resources and to determine our own future.

Fortis today is still convinced of the necessity of volume, on a national scale as well as on a really world-wide scale. Our wish to determine our own future has not changed either. At the same time, I am sure that new mergers and acquisitions are to be expected in the financial services industry. Taking into account our positive experiences with transnational 
concentration, and considering the position of Europe compared with the position of the USA and Japan I expect more transnational movements in the financial services sector in the years to come, and especially in Europe.

Transnational mergers certainly are a great challenge. They also offer great opportunities, provided that the parties involved really wish to accomplish something together. Because, as I observed earlier, aiming for success together means, first and last, that you have to support a common vision and plan together. Together building one group, together striving for unity depends more than anything else on our involvement as people, on a personal level. Only if you totally put yourself in the other person's shoes and really try to understand each other, only then will it be possible to communicate effectively and create together a successful, high-performance transnational group.

\section{Fortis-Key figures}

1. General figures

\begin{tabular}{lrrr}
\hline & & & $\begin{array}{r}\text { Increase } \\
\text { in \% }\end{array}$ \\
\hline Fortis (in ECU million) & 1994 & 1993 & \\
Total income & $16,316.9$ & $9,552.5$ & 71 \\
Operating result ( ${ }^{*}$ ) & 766.4 & 478.2 & 60 \\
Net profit & 549.1 & 476.2 & 15 \\
Net equity & $4,288.8$ & $4,083.8$ & \\
Fortis AMEV (in NLG) & & & \\
Earnings per share & 8.74 & 8.12 & 12 \\
Dividend per share & 3.80 & 3.40 & \\
Pay-out (in \%) & 43 & 42 & \\
Fortis AG (in BEF) & & & \\
Earnings per share & 285 & 242 & 30 \\
Dividend per share & 100 & 76.77 & \\
Pay-out (in \%) & 35 & 32 &
\end{tabular}

(*) The operating result is the result before taxation excluding capital gains/losses and exceptional revenues and charges, and including third-party interests.

2. Key figures insurance (in ECU million)

\begin{tabular}{lrrrr}
\hline & & & Increase in \% \\
\cline { 3 - 5 } & 1994 & 1993 & Total & Autonomous $\left(^{*}\right)$ \\
\hline Premium income & $7,419.6$ & $5,850.5$ & 27 & 13 \\
Total revenues & $10,079.1$ & $8,203.9$ & 23 & 9 \\
$\begin{array}{l}\text { Operating result } \\
\text { ( }) \text { Excluding the effect of acquisitions and divestments of group companies and exchange rate fluctua- } \\
\text { tions. }\end{array}$ \\
\hline
\end{tabular}




\begin{tabular}{lrrrr}
\hline & & & \multicolumn{2}{c}{ Increase in \% } \\
\cline { 3 - 5 } & 1994 & 1993 & Total & Autonomous \\
\hline Interest receivable & $5,634.2$ & $1,039.7$ & $*$ & $(6)$ \\
Other income & 594.8 & 314.9 & 89 & $(7)$ \\
Operating result & 253.2 & 86.4 & $*$ & $(1)$ \\
Balance sheet total & $66,778.7$ & $63,427.7$ & 5 & \\
\hline
\end{tabular}

\section{Balance sheet total}

The balance sheet totals at 31 December 1994 and 1993 (in ECU million) were as follows:

\begin{tabular}{lrr}
\hline & 1994 & 1993 \\
\hline Insurance & $36,866.5$ & $34,264.8$ \\
Banking & $66,778.7$ & $63,427.7$ \\
General $\left(^{*}\right)$ & 676.4 & 736.7 \\
Intercompany accounts & $(824.4)$ & $(842.1)$ \\
& $103,497.2$ & $97,587.1$
\end{tabular}

(*) This includes the balance sheet totals of the holding companies in which the activities are included which are not attributable to the insurance or banking sector or a geographical area. 